\title{
FORMULATION AND EVALUATION OF FUROSEMIDE LIQUISOLID COMPACT
}

\author{
ZAINAB E. JASSIM* \\ *Department of Pharmaceutics, College of Pharmacy, University of Baghdad, Iraq, Baghdad \\ Email: zainabeassaf@gmail.com
}

Received: 19 Jul 2017, Revised and Accepted: 10 Oct 2017

\section{ABSTRACT}

Objective: The purpose of this study was to enhance the dissolution pattern of the practically water-insoluble diuretic drug, furosemide through its formulation into liquisolid tablets.

Methods: A mathematical model was used to formulate four liquisolid powder systems using polyethylene glycol 400 as a non-volatile water miscible liquid vehicle. The liquid loading factors of the vehicle were used to calculate the optimum quantities of carrier (Avicel PH 102) and coating materials (Aerosil 200) needed to prepare acceptably flowing and compactible powder mixtures and (R) ratio used was 25. The liquisolid tablets were evaluated for weight variation, percent friability, hardness, content uniformity, disintegration time and in vitro drug release profile. Drug and the prepared systems were characterized by fourier transform infrared spectroscopy (FTIR), differential scanning calorimetry (DSC) and powder xray diffraction (PXRD) studies.

Results: The enhanced dissolution rate due to the increased wetting properties and the large available surface areas for dissolution were obtained in case of the liquisolid tablets. The selected optimal formulation (F2) of 50\% drug concentration released $90 \%$ of its content during the first 10 min compared to $65 \%$ of DCT. FTIR studies revealed that there was no interaction between drug and polymers. DSC and PXRD indicated conversion of crystalline to amorphous form of furosemide.

Conclusion: The dissolution rate of furosemide can be enhanced to a great extent by liquisolid technique.

Keywords: Furosemide, Liquisolid compact, PEG 400, Co-processed super disintegrant, Solvent evaporation method

(C) 2017 The Authors. Published by Innovare Academic Sciences Pvt Ltd. This is an open access article under the CC BY license (http://creativecommons.org/licenses/by/4.0/) DOI: http://dx.doi.org/10.22159/ijap.2017v9i6.21458

\section{INTRODUCTION}

The poor dissolution rate of water-insoluble drugs confronts a major obstacle in the development of pharmaceutical dosage forms. The drugs which are poorly water soluble will be released at a slow rate owing to their limited solubility within gastrointestinal tract [1]. In general drugs with low aqueous solubility (lower than $100 \mu \mathrm{g} / \mathrm{ml}$ ) show dissolution-limited and incomplete absorption from the gastrointestinal tract of animals and humans [2].

The various properties of drug-like solubility, particle size, polymorphism, salt form, complexation, wettability affect drug dissolution and its rate and can be targeted to enhance dissolution of poorly water-soluble drugs [3]. Some commonly used physical modifications to enhance the dissolution of API includes: (a) Reducing particle size to increase surface area, thus increasing dissolution rate of drug, (b) solubilization in surfactant systems, (c) formation of water-soluble complexes, (d) drug derivatization such as a strong electrolyte salt form that usually has higher dissolution rate, and (e) manipulation of solid state of drug substance to improve drug dissolution, i.e., by decreasing crystallinity of drug substance through formation of solid solutions [4].

The most promising and new technique for promoting dissolution is the formation of liquisolid tablets among the various novel techniques. Liquisolid compacts promote dissolution rate of water-insoluble drugs to a greater extent and also enhances the drug flow property [5].

The liquisolid technique is a novel and most promising technique for improving the dissolution rate of poorly water-soluble drugs. With the liquisolid technology, a liquid may be transformed into a freeflowing, readily compressible and apparently dry powder by simple physical blending with selected excipients named the carrier and coating material $[5,6]$.

Furosemide is 5-(Aminosulfonyl)-4-chloro-2-[(2-furanyl methyl) amino] benzoic acid (fig. 1), the empirical formula is $\mathrm{C}_{12} \mathrm{H}_{11} \mathrm{ClN}_{2} \mathrm{O}_{5} \mathrm{~S}$ corresponds to the molecular weight of 330.77. Furosemide is a white to slightly yellow, odourless, almost tasteless crystalline powder, slightly soluble in water, chloroform and ether, soluble in acetone, methanol, dimethyl formamide and in solutions of alkali hydroxides. Its melting point is $206^{\circ} \mathrm{C}$ [7].<smiles>NS(=O)(=O)c1cc(C(=O)O)c(NCc2ccco2)cc1Cl</smiles>

Fig. 1: Chemical structure of furosemide [8]

Furosemide is a loop diuretic act primarily by inhibiting chloride and sodium reabsorption over the entire length of the thick ascending limb of the loop of Henle, it is widely used for the symptomatic treatment of heart failure and fluid retention in chronic kidney disease [9].

The present research work was aimed to prepare furosemide liquisolid compact and to enhance the solubility and dissolution rate of furosemide by liquisolid technique.

\section{MATERIALS AND METHODS}

The following gift samples were received: furosemide from (Awa medica, Erbil), microcrystalline cellulose PH 102 (FMC, USA), Aerosil 200 and crospovidone (Wuhan Senwayer Century chemical Co., Ltd), PEG 400, and sodium starch glycolate (were obtained from SD Fine Chem Ltd., Mumbai, India), magnesium stearate (Robert E. M. TILG, Germany). All reagents used were of analytical grade.

\section{Methods}

\section{Solubility studies}

Solubility studies of furosemide were carried out in water, phosphate buffer pH 5.8 and polyethene glycol (PEG 400). Saturated solutions were prepared by adding an excess drug to the vehicle and shaking in a water bath with a shaker for $48 \mathrm{~h}$ at $25 \pm 0.5{ }^{\circ} \mathrm{C}$ under 
constant vibration. After this period the solutions were filtered, diluted and analyzed by UV spectrophotometer (Cary, Australia) at $277 \mathrm{~nm}$. Three determinations were carried out for each sample to calculate the solubility of furosemide.

\section{Application of the mathematical model for designing the liquisolid systems}

The formulation design of liquisolid systems was done in accordance with new mathematical model described by Spireas et al.

In this study, PEG 400, microcrystalline cellulose (Avicel ${ }^{\circledR}$ PH 102MCC), and Aerosil ${ }^{\circledR} 200$ were used as a liquid vehicle, carrier and coating materials respectively. The concentration of the drug in liquid vehicle was varied and the carrier: coating ratio was kept constant in all formulations $(\mathrm{R}=25: 1)$.

Depending on the excipient ratio $(R)$ of the powder substrate an acceptably flowing and compressible liquisolid system can be obtained only if a maximum liquid load on the carrier material is not exceeded. This liquid/carrier ratio is termed "liquid load factor $\mathrm{L}_{\mathrm{f}}$ $[\mathrm{w} / \mathrm{w}]$ and is defined as the weight ratio of the liquid formulation $(W)$ and the carrier material $(Q)$ in the system:

$$
\mathrm{Lf}_{\mathrm{f}}=\mathrm{W} / \mathrm{Q} \text {----- }(1)
$$

$R$ represents the ratio between the weights of the carrier $(Q)$ and the coating $(q)$ material present in the formulation:

$$
\mathrm{R}=\mathrm{Q} / \mathrm{q}-----(2)
$$

The liquid load factor that ensures acceptable flowability (Lf) can be determined by:

$$
\mathrm{Lf}=\Phi+\varphi \cdot(1 / \mathrm{R})----(3)
$$

Where $\sqrt{ }$ and $\varphi$ are the $\Phi$-values of the carrier and coating material, respectively [10].

In order to calculate the required ingredient quantities, the flowable liquid retention potentials ( $\Phi$-values) of powder excipients were utilized. In polyethylene glycol 400, the $\Phi$-value of Avicel PH 102 was found to be 0.005 and the $\varphi$-value for Aerosil 200 was 3.26 [11].

So, by knowing both Lf and W, the appropriate quantities of carrier (Q) and coating $(\mathrm{q})$ powder materials required to convert a given amount of liquid medication (W) into an acceptably flowing and compressible liquisolid system could be calculated from equation (1) and (2).

\section{Preparation of co-processed superdisintegrant}

The co-processed superdisintegrants were prepared by solvent evaporation method. A blend of crospovidone and sodium starch glycolate (in the ratio 1:1) was added to $10 \mathrm{ml}$ of ethanol. The contents of the beaker ( $250 \mathrm{ml}$ capacity) were mixed thoroughly and stirring was continued until most of the ethanol evaporated. The wet coherent mass was granulated through \#44 mesh sieve.

The wet granules were dried in a hot air oven at $60 \mathrm{C}^{\circ}$ for $20 \mathrm{~min}$. The dried granules were sifted through \#44 mesh sieve and stored in an airtight container until further use [12,13].

The co-processed superdisintegrants at a ratio (1:1) was used in the preparation of liquisolid compacts to study the effect of coprocessed superdisintegrants on the disintegration and dissolution rate of furosemide liquisolid compacts.

\section{Preparation of furosemide liquisolid compact}

Four liquisolid tablets denoted (F1 to F4) containing $40 \mathrm{mg}$ of furosemid were prepared by dispersing in the non-volatile vehicle (PEG 400). Then a bindery mixture of the carrier (Avicel PH 102) and coating material (Aerosil 200) was prepared at a ratio of 25: 1, by continuous mixing for a period of $10 \mathrm{~min}$ in a mortar. The amount of carrier and coating materials are enough to maintain acceptable flow and compression properties. R 25 was used in all formulations since it gave the optimal flow property.

Finally, a $5 \% \mathrm{w} / \mathrm{w}$ of co-processed superdisintegrant (crospovidone and sodium starch glycolate at ratio 1:1) was added and mixed for $10 \mathrm{~min}$ then $1 \% \mathrm{w} / \mathrm{w}$ of magnesium stearate as a lubricant was added into the mixture and mixed for $2 \mathrm{~min}$. The final mixture was compacted using a single punch-tablet machine (Korsch EKO, Germany) [14]. The composition of liquisolid tablets is shown in table 1.

\section{Preparation of direct conventional tablet of furosemide}

Furosemide conventional tablets were produced by mixing the drug with Avicel PH 102 and aerocil 200 (ratio of microcrystalline cellulose: aerocil was 25:1) for a period of $10 \mathrm{~min}$ in a mortar without the addition of the vehicle. The mixture then was mixed with $(5 \%)$ of co-processed super-disintegrant (1:1) for $10 \mathrm{~min}$, and then $(1 \%)$ of magnesium stearate was mixed for $2 \mathrm{~min}$. The mixture was compressed using a single punch tablet machine (Korsch,

\begin{tabular}{|c|c|c|c|c|c|c|c|c|c|c|}
\hline Formulas & $\begin{array}{l}\text { Furosemide } \\
\text { concentration in } \\
\text { liquid medication } \\
(\% \mathrm{w} / \mathrm{w})\end{array}$ & $\begin{array}{l}\text { (R) } \\
Q: q\end{array}$ & $\begin{array}{l}\text { Loading } \\
\text { factor } \\
\text { (Lf) } W / Q\end{array}$ & $\begin{array}{l}\text { PEG } \\
\text { 400 } \\
(\mathrm{mg})\end{array}$ & $\begin{array}{l}\text { Furosemide } \\
\text { (mg) }\end{array}$ & $\begin{array}{l}\text { MCC PH } \\
102 \\
Q \text { (mg) }\end{array}$ & $\begin{array}{l}\text { Aerosil }^{\circledR} \\
200 \\
\text { q (mg) }\end{array}$ & $\begin{array}{l}\text { Co-processed } \\
\text { superdisintegrant } \\
(1: 1) 5 \%(\mathrm{mg})\end{array}$ & $\begin{array}{l}\text { Magnesium } \\
\text { stearate 1\% } \\
\text { (mg) }\end{array}$ & $\begin{array}{l}\text { Unit } \\
\text { dose } \\
\text { (mg) }\end{array}$ \\
\hline F1 & 40 & 25 & 0.1354 & 60 & 40 & 738.6 & 30 & 43 & 9.1 & 920.7 \\
\hline $\mathrm{F} 2$ & 50 & 25 & 0.1354 & 40 & 40 & 591 & 24 & 35 & 7.3 & 737.3 \\
\hline F3 & 60 & 25 & 0.1354 & 27 & 40 & 495 & 20 & 29 & 6.11 & 617.11 \\
\hline F4 & 70 & 25 & 0.1354 & 17 & 40 & 421 & 17 & 25 & 5.2 & 525.2 \\
\hline
\end{tabular}
Germany). This formulation was denoted as DCT [15].

Table 1: Formulation of furosemide liquisolid tablets using PEG-400

Excipient ratio, $\mathrm{R}=\mathrm{Q} / \mathrm{q}, \mathrm{Q}=$ Weight of carrier, $\mathrm{q}=$ Weight of coating material, Liquid load factor, $\mathrm{Lf}=\mathrm{W} / \mathrm{Q}$, W= Weight of liquid medication, $\mathrm{Q}=\mathrm{Weight}$ of carrier

\section{Pre-compression studies}

\section{Characterization of powder mixture}

\section{Angle of repose}

The frictional force of a loose powder can be measured by the angle of repose $(\theta)$. The fixed funnel method was employed to measure the angle of repose. A funnel was secured with its tip at a given height (h), above a Petri dish is placed on a flat horizontal surface. The blend carefully pored through the funnel until the apex of the conical pile just touches the tip of the funnel. The radius (r) of the base of the conical pile was measured.

The angle of repose $(\theta)$ was calculated using the following formula:
$\operatorname{Tan} \theta=h / r$

Where; $\theta=$ angle of repose, $\mathrm{h}=$ height of the cone in $\mathrm{cm}, \mathrm{r}=$ radius of the cone base in $\mathrm{cm}[16]$.

\section{Bulk and tapped density}

An accurately weighed quantity of the liquisolid powder (w) was carefully poured into the graduated cylinder and the volume (vo) was measured. The graduated measuring cylinder was tapped for 1000 times and after that, the volume (vf) was measured. The bulk density and tapped density were calculated using the formulas below:

Bulk density $=\frac{w}{v o}$ 


$$
\text { Taped density }=\frac{w}{v f}
$$

Where $\mathrm{w}$ is the weight of powder, vo is the initial volume and vf is the final volume.

From the results of bulk density and tapped density, carr's index was calculated [17]

$$
\text { Carr's index }=\frac{\text { Tapped density-Bulk density }}{\text { Tapped density }} \mathrm{x} 100
$$

\section{Post-compression studies}

\section{Hardness}

The hardness of the tablet was determined using Monsanto hardness tester. Three tablets were randomly selected from each formulation and hardness of the same was determined. The average value was calculated [14].

\section{Friability testing}

Friability of the tablets was determined by using Roche friabilator. A number of tablets (equal to $6.5 \mathrm{~g}$ or more in weight) were placed in the friabilator and rotated at $25 \mathrm{rpm}$ for a period of $4 \mathrm{~min}$. The friability was determined using the following formula:

$$
\text { Percentage friability }=\frac{\mathrm{w} 1-\mathrm{W} 2}{\mathrm{~W} 1} \times 100
$$

Where $\mathrm{W} 1=$ initial weight of tablets, $\mathrm{W} 2=$ weight of the tablets after testing $[15,18]$.

\section{Content uniformity}

The drug content of the tablets was measured according to united state pharmacopoeia USP. Ten tablets were selected randomly from each formula; each tablet was crushed in a mortar and transferred it into a $100 \mathrm{ml}$ volumetric flask and sonicated for $10 \mathrm{~min}$. Then volume made up to $100 \mathrm{ml}$ with phosphate buffer $\mathrm{pH} 5.8$. Then $1 \mathrm{ml}$ of resultant solution diluted to $100 \mathrm{ml}$ with buffer solution $\mathrm{pH} 5.8$. Measure the absorbance of above solution using UV spectrophotometer at $277 \mathrm{~nm}$ [19].

\section{Weight variation}

Twenty tablets were weighed individually and then all together. Average weight was calculated from the total weight of all tablets. The individual weights were compared with the average weight. The percentage difference in the weight variation should be within the permissible limits as specified in USP, not more than two tablets should differ in their average weight by more than percentages stated in USP. No tablet must differ by more than double the relevant percentage [20].

\section{Disintegration test}

The disintegration time was determined in water maintained at $37 \pm 2^{\circ} \mathrm{C}$. The disintegration apparatus with a basket rack assembly containing six open-ended tubes and 10-mesh screen on the bottom was used. A tablet was placed in each tube of the basket and the time for complete disintegration of the six tablets was recorded [21-23].

\section{In vitro dissolution test}

The dissolution rates of all formulations were measured by using tablet dissolution apparatus USP Type II. Dissolution studies were carried out using $900 \mathrm{ml}$ of phosphate buffer $\mathrm{pH} \mathrm{5.8,} \mathrm{at} 50 \mathrm{rpm}$ and at a temperature of $37 \pm 0.5^{\circ} \mathrm{C}$. $10 \mathrm{ml}$ of the medium was withdrawn at a suitable time interval, filtered and diluted with phosphate buffer $\mathrm{pH}$ 5.8. Sink conditions were maintained throughout the study. The samples were then analyzed at $277 \mathrm{~nm}$ by UV/visible spectrophotometer. The study was carried out in triplicate $[15,24]$.

\section{Dissolution data evaluation}

For the comparison of dissolution data for each formulation, percentages of drug dissolved at $10 \mathrm{~min}$ (Q10 min), mean dissolution time (MDT) and percentage of dissolution efficiency
(\%DE) at the end of 60 min were calculated using DDsolver software in order to select the optimized formula.

The model-independent approach includes the difference factor ( $f 1$ ) and the similarity factor $(f 2)$ was used to compare between the dissolution profile of optimized formula and the DCT. The $f 1$ factor measures the percentage error between two curves over all time points:

$$
\mathrm{f} 1=\frac{\sum_{\mathrm{t}}^{\mathrm{n}}=1|\mathrm{Rt}-\mathrm{Tt}|}{\sum_{\mathrm{t}}^{\mathrm{n}}=1 \mathrm{Rt}} \times 100
$$

Where $\mathrm{n}$ is the number of time points and $\mathrm{Rt}$ and $\mathrm{Tt}$ are the percentages of the reference and test product dissolved, respectively, at each time point. The percentage error is zero when the test and drug reference profiles are identical and increases proportionally with the dissimilarity between the two dissolution profiles [25].

The similarity factor $(f 2)$ is a logarithmic transformation of the sumsquared error of differences of drug percentage dissolved between the test and the reference products over all time points:

$$
\left.f_{2}=50 \log \left\{\left[1+\frac{1}{n} \sum_{t=1}^{n}\left(R_{t}-T_{t}\right)\right)\right]^{-0.5} \times 100\right\}
$$

Where $\mathrm{n}$ is the number of time points at which \% dissolved was determined, $\mathrm{Rt}$ is the \% dissolved of one formulation at a given time point, and $\mathrm{Tt}$ is the \% dissolved of the formulation to be compared at the same time point [26].

\section{Differential scanning calorimetry (DSC)}

Samples (3-5 mg) were placed in an aluminum pan and heated in the DSC 60-plus (Shimadzu, Japan) at a constant rate of 10 ${ }^{\circ} \mathrm{C} / \mathrm{min}$, in an atmosphere of nitrogen over a temperature range of $25-300{ }^{\circ} \mathrm{C}$. The DSC studies were performed on the pure drug, a physical mixture of the optimized liquisolid system, and on the liquisolid tablet [27].

\section{Fourier-transform infrared spectroscopy (FTIR)}

It was performed using the infrared spectrophotometer (Lambda 7600 , Australia). Samples of 2-3 mg were mixed with about $100 \mathrm{mg}$ of dry potassium bromide powder and compressed into transparent discs then scanned over a wave range of 4000-400 $\mathrm{cm}^{-1}$ in FTIR instrument. FTIR spectra were performed on the pure drug, sodium starch glycolate, crospovidone, co-processed superdisintegrant at a ratio (1:1), a physical mixture of optimized liquisolid system and on the liquisolid tablet [28].

\section{$\mathrm{X}$-ray powder diffraction (XRPD)}

X-ray diffractograms of pure furosemide, physical mixture of liqisolid and liquisolid tablet were obtained using analytical XRD instrument. The scanning range was from 5 to $60^{\circ}$ at 2 theta scale and 5 degree/min. The voltage and strength of the electric current were $40 \mathrm{KV}$ and $30 \mathrm{~mA}$, respectively [29].

\section{Statistical analysis}

All the results were expressed as the mean value \pm standard deviation (SD). T-test was used to test for significance, at a $5 \%$ significance level. Statistical difference dealing $(\mathrm{P}<0.05)$ was considered significant [30].

\section{RESULTS AND DISCUSSION}

\section{Saturation solubility studies}

The solubility of furosemide in different media is presented in table 2. Drug solubility in a non-volatile vehicle is the most important aspect in liquisolid systems. The solubility of the drug contributes to molecular dispersion in a non-volatile solvent which will improve the dissolution rate.

The solubility of furosemide in macrogol $400(98.69 \mathrm{mg} / \mathrm{ml})$ was approximately 10000 times higher than in water $(0.006 \mathrm{mg} / \mathrm{ml})$. 
Table 2: Solubility of furosemide in various media

\begin{tabular}{ll}
\hline Medium & Solubility (mg/ml) \pm SD $^{*}$ \\
\hline Distilled water & $0.006 \pm 0.9$ \\
Phosphate buffer pH 5.8 & $0.72 \pm 2$ \\
PEG 400 & $98.69 \pm 1.4$ \\
\hline
\end{tabular}

* Results were expressed in mean \pm SD $(n=3)$, SD standard deviation

\section{Flowable liquid retention potential ( $\Phi$ value) and liquid load} factor (Lf)

$\Phi$ value of carrier and coating materials in polyethene glycol 400 were cited in the literature and found to be 0.005 and 3.26 respectively. According to mathematical model proposed by Spireas et al. equation for Avicel PH-102 and Aerosil 200 in polyethene glycol 400 was calculated by using R-value $=25$ as

$$
\begin{gathered}
\mathbf{L f}=\mathbf{0 . 0 0 5}+\mathbf{3 . 2 6}(\mathbf{1} / \mathbf{R}) \\
\text { So, Lf }=0.1354
\end{gathered}
$$

\section{Pre-compression evaluation}

\section{Angle of repose}

Angle of repose provides a qualitative and quantitative assessment of internal cohesive and frictional force under low level of external load applied during mixing and tableting. Values less than 35 indicate good flow whereas greater than 35 indicates poor flow.
The results of the angle of repose and carr's index were given in the table 3. The results showed that angle of repose was ranged from $30.8^{\circ}$ to $34.8^{\circ}$. It was found that formula of highest drug concentration in PEG 400 has better flowability than another formula due to fewer amounts of vehicle presents on the surface of the carriers in liquisolid formulations.

We could not increase the $\mathrm{R}$ in order to enhance the flowability because the tablet weight will increase above $1 \mathrm{gm}$ and difficult to be compressed by the available tablet machine.

\section{Hardness test}

Hardness of the prepared tablets of all formulations is within the acceptable limit. Hardness of tablets prepared by direct compression was found to be from 3 to $10 \mathrm{~kg} / \mathrm{cm}^{2}$ as shown in table 4 . Generally, the ideal tablet hardness should be produced without applying excessive compression force where rapid tablet disintegration and drug dissolution are maintained at the same time [31].

Table 3: Flow properties of furosemide liquisolid powder and DCT

\begin{tabular}{lllll}
\hline Formula & Angle of repose* & Type of flow & Carr's index* & Type of flow \\
\hline F1 & $34.8 \pm 0.85$ & good & good & $14.5 \pm 2.5$ \\
F2 & $32 \pm 2.8$ & good & $18.1 \pm 2.5$ & Fair \\
F3 & $31.9 \pm 1.5$ & good & $21 \pm 2$ & passable \\
F4 & $30.8 \pm 3$ & good & $21.4 \pm 4$ & passable \\
DCT & $33.6 \pm 0.5$ & fair & $19 \pm 1$ & \\
\hline
\end{tabular}

*Results were expressed in mean \pm SD ( $n=3$ ), SD standard deviation, DCT: direct conventional tablet

\section{Friability test}

All furosemide tablets had acceptable friability as none of the tested formulas exceeded $1 \%$ loss in tablet weight as shown in table 4; also, no tablet was cracked, split or broken in either formulation. Since all the prepared formulas met the standard friability criteria, they are expected to show acceptable durability and withstand abrasion. Formulations containing a higher level of nonvolatile solvent were able to reflect greater interparticulate bonding between particles, resulting in low friability percent [32].

\section{Disintegration time}

The disintegration time for the prepared furosemide liquisolid tablets was shown in table 4. It was found that the mean of the disintegration times for all investigated tablets was less than $1 \mathrm{~min}$, due to the effect of co-processed super disintegrant. Co-processing of excipients could lead to the formation of excipients with superior properties compared with a simple physical mixture of their components or with individual components [33].
Co-processed superdisintegrant accelerated the disintegration of tablets by virtue of its ability to absorb a large amount of water when exposed to an aqueous environment [34]. The results reveal that coprocessing resulted in the formation of quickly disintegrating tablets. The probable reason for the faster disintegration could be the development of a higher disintegration force, this force generated by disintegrant particles is more critical than the actual swelling because this force is responsible for the breaking up of the tablet [35].

Also due to high Avicel pH 102 content, where Avicel PH 102 functions as a swellable disintegrant, in combination with hydrophilic solvent PEG 400, which improves wetting properties of the obtained liquisolid tablets and hence facilitate the volume expansion of superdisintegrant [36].

\section{Weight variation}

Tablets of each formula were subjected to weight variation test, the difference in weight and percent deviation was calculated for each tablet. The results of the test showed that the tablet weights were within pharmacopoeia limit as shown in table 4.

\begin{tabular}{|c|c|c|c|c|c|}
\hline Formula & $\begin{array}{l}\text { Hardness* } \\
\left(\mathrm{Kg} / \mathrm{cm}^{2}\right)(\text { mean } \pm \text { SD) }\end{array}$ & $\begin{array}{l}\text { Friability } \\
(\%)\end{array}$ & $\begin{array}{l}\text { Disintegration time* } \\
\text { (s) }(\text { mean } \pm S D)\end{array}$ & $\begin{array}{l}\text { Content uniformity* } \\
\% \text { (mean } \pm \text { SD) }\end{array}$ & $\begin{array}{l}\text { Weight variation* } \\
\text { (mg) (mean } \pm \text { SD) }\end{array}$ \\
\hline F1 & $3 \pm 1$ & 0.12 & $30 \pm 0.9$ & $96.6 \pm 2$ & $932.9 \pm 4.94$ \\
\hline $\mathrm{F} 2$ & $3.7 \pm 0.577$ & 0.14 & $28 \pm 1.032$ & $97 \pm 1$ & $743.15 \pm 4$ \\
\hline F3 & $3.5 \pm 0.5$ & 0.28 & $24 \pm 0.81$ & $99.6 \pm 0.8$ & $621.55 \pm 2.9$ \\
\hline $\mathrm{F} 4$ & $6.8 \pm 0.29$ & 0.29 & $29 \pm 1.2$ & $97 \pm 0.86$ & $511.15 \pm 3$ \\
\hline DCT & $10 \pm 2$ & 0.5 & $31 \pm 0.2$ & $99 \pm 0.9$ & $732.5 \pm 3$ \\
\hline
\end{tabular}

Table 4: Hardness, friability, disintegration time, drug content and weight variation of furosemide liquisolid tablets and DCT

* Results were expressed in mean \pm SD $(n=3)$, SD standard deviation, DCT: direct conventional tablet, s: second 


\section{Drug content}

The drug content for tablets of all the formulations ranges from 96.6-99.6\% (table 4). The results indicate that the contents for tablets of all the formulations were uniform and contains a therapeutic dose of the active ingredients.

\section{In vitro dissolution test}

The results of in vitro drug released are plotted against time in phosphate buffer solution $\mathrm{pH} 5.8$ to obtain the dissolution profiles as shown in fig. 2 and 3. MDT, Q10 min, and \% DE of each liquisolid formula and DCT were calculated and reported in table 5 .

Table 5: Model-independent parameters of liquisolid compacts and DCT

\begin{tabular}{llll}
\hline Formula & Q10 min & MDT (min) & \%DE \\
\hline F1 & $74 \%$ & 7.85 & 87 \\
F2 & $90 \%$ & 5.9 & 90 \\
F3 & $67 \%$ & 9.9 & 84 \\
F4 & $78 \%$ & 9.4 & 84 \\
DCT & $65 \%$ & 13.8 & 77 \\
\hline
\end{tabular}

Q10 min: percentages of drug dissolved at 10 min, MDT: mean dissolution time, DE: dissolution efficiency, DCT: direct conventional tablet. Values was represented as mean \pm SD

The percentage of furosemide released from liquisolid compacts containing PEG 400 (from F1 to F4) was found to vary from $67 \pm 0.32 \%$ to $90 \pm 0.78 \%$ in first $10 \mathrm{~min}$, while $65 \% \pm 0.3$ of drug release from DCT. This indicates fast release of the drug is observed from above liquisolid tablets.

From the calculations of \%DE and MDT, F2 (at drug concentration $50 \% \mathrm{w} / \mathrm{w}$ in liquid medication) formulation showed better improvement in dissolution and it is considered as optimized formulation. The reduction in mean dissolution time (MDT) values indicates the faster release of drug from formulation F2 compared to other formulations.

The release of furosemide from F2 was also compared with DCT (fig. 3) prepared in a similar manner without nonvolatile liquid to study the effect of nonvolatile solvents on drug dissolution.

The release from DCT was $78 \%$ in 30 min compared to complete drug release from the liquisolid formulation. The difference in dissolution was found to be significant $(\mathrm{p}<0.05)$ using student's $t-$ test analysis. This clearly indicates the improvement in the dissolution of furosemide was due to the presence of the drug in nonvolatile solvent in the liquisolid formulation.

The increased dissolution from liquisolid formulation could be due to the presence of the drug insoluble state in the formulation, which contributes to the increased wetting properties, thereby enhancing the dissolution rate. Similarly, as the formulation disintegrates in dissolution media, the drug will be presented in a state of molecular dispersion. This will increase the effective surface area of the particles available for dissolution [15].

Concerning the drug concentration in the liquid vehicle, as the drug concentration decreased, the portion solubilized and molecularly dispersed in the liquid vehicle increased thus leading to better dissolution [37-39].

In addition, the more vehicles available, the more even the distribution of the vehicle over the remaining undissolved drug particles that would help in better wetting of the drug through the dissolution stage [40].

A pairwise procedure such as dissimilarity ( $f 1)$ and similarity ( $f 2)$ factors provides a simple way to compare dissolution data. Food and drug administration (FDA) guidance proposes that $f 1$ value between 0 and 15 and $f 2$ value between 50-100 indicate equivalence in dissolution profiles $[25,26]$. In comparison between the dissolution of F2 and the DCT, the results of $f 1$ and $f 2$ were 16.22 and 36.18 respectively gave an indication that the two dissolution profiles are equivalent.

\section{Differential scanning calorimetry (DSC)}

The differential scanning calorimetry (DSC) thermograms of furosemide, a physical mixture of F2 liquisolid and F2 liquisolid tablet are illustrated in fig. 4, 5 and 6 respectively. Furosemide exhibits two characteristics, sharp endothermic peak at $218.16^{\circ} \mathrm{C}$ and exothermic peak at $222.32^{\circ} \mathrm{C}$, which are associated with the decomposition and melting points of the drug and indicate the crystalline nature of the drug $[41,42]$. The physical mixture of liquisolid and liquisolid tablet showed the partial disappearance of the characteristic peak of furosemide, supporting the probable phenomena of getting molecularly dispersed into the liquisolid matrix system, which suggests conversion of the drug into an amorphous form. This supports the in vitro release studies data of improved drug release and indicating no interaction between furosemide and excipients [43].

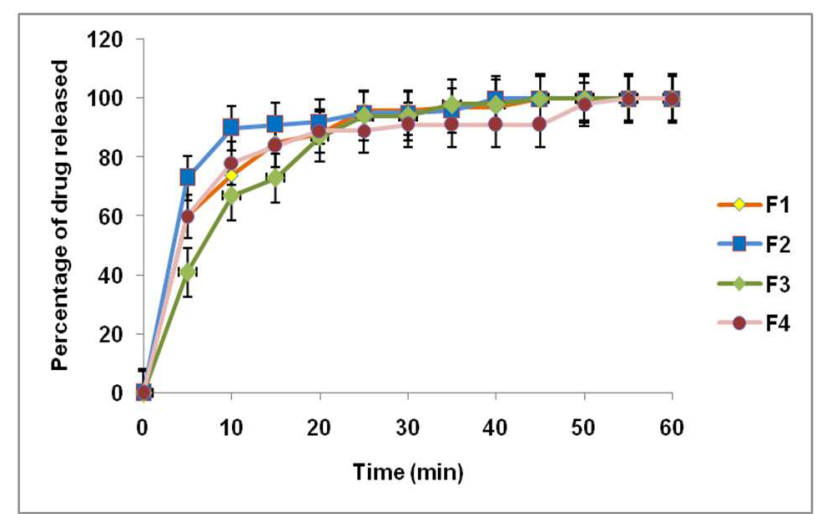

Fig. 2: Dissolution profile of furosemide from liquisolid tablets (values represent mean $\pm S D, n=3$ )

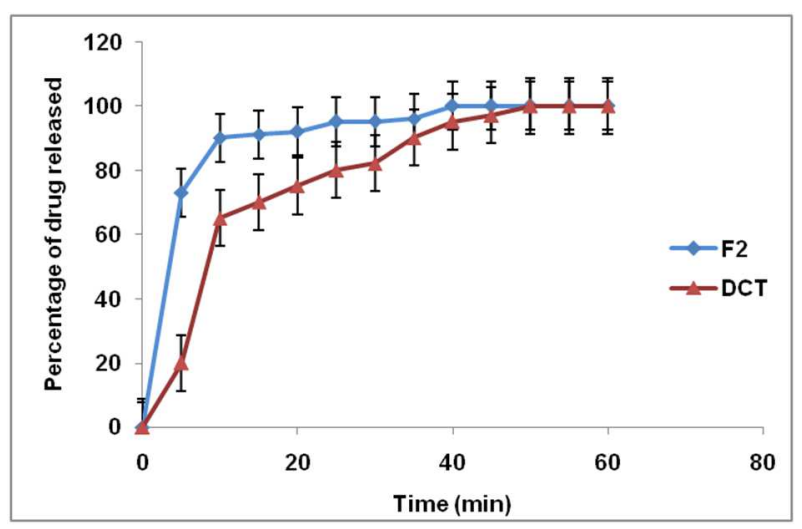

Fig.3: Dissolution profile of furosemide from F2 and DCT (values represent mean $\pm S D, n=3$ ), DCT: direct conventional tablet 


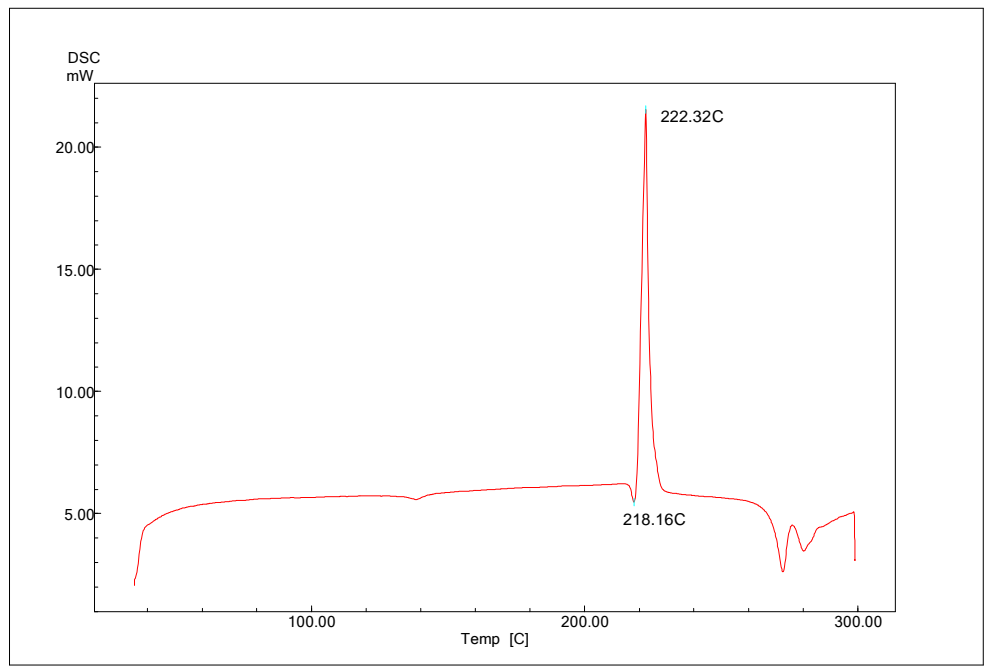

Fig. 4: DSC thermogram of furosemide

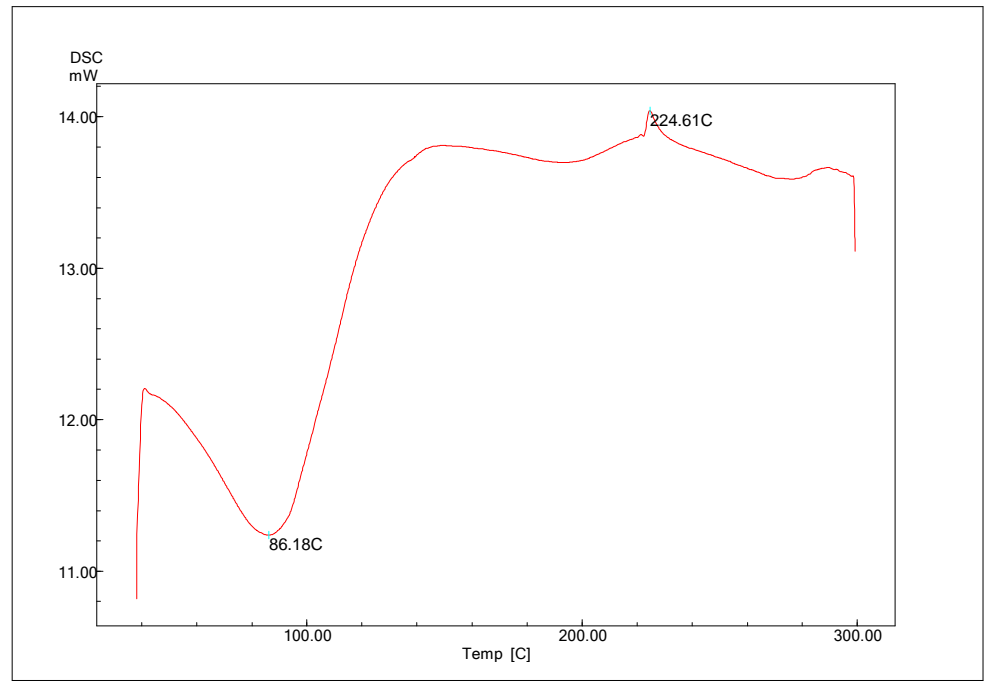

Fig. 5: DSC thermogram of physical mixture of F2 liquisolid

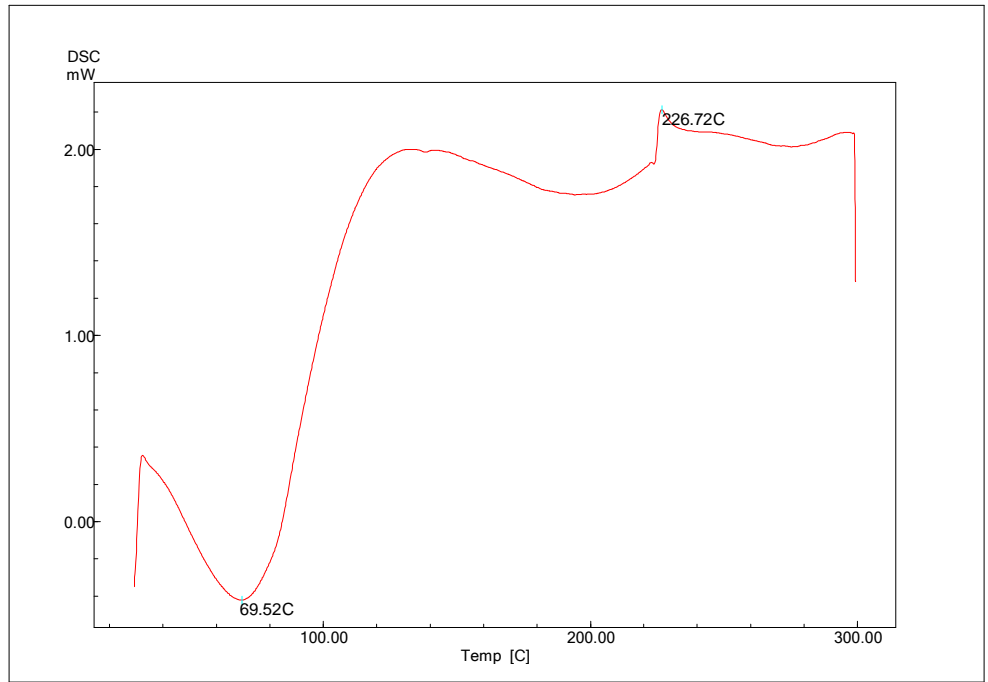

Fig. 6: DSC thermogram of F2 liquisolid tablet 


\section{Fourier-transform infrared spectroscopy (FTIR)}

FTIR was performed to detect any sign of interaction which would be reflected by a change in the position or disappearance of any characteristic stretching vibration of furosemide. Fig. 7 showed the characteristic peaks of furosemide of N-H stretching at $3399 \mathrm{~cm}^{-1}, \mathrm{~N}-$ $\mathrm{H}$ stretching in sulfonamide at 3349 and $3284 \mathrm{~cm}^{-1}$. The $\mathrm{C}=0$ stretching, the vibration was at $1671 \mathrm{~cm}^{-1}, \mathrm{~S}=0$ stretching, vibration at $1141 \mathrm{~cm}^{-1}$ and $1322 \mathrm{~cm}^{-1}$, most important stretching vibration was $\mathrm{OH}$ stretching at $3122 \mathrm{~cm}^{-1}$, NH bending at $1563-1590 \mathrm{~cm}^{-1}$ [44].

As shown in fig. 8 and 9 respectively, The FTIR spectra of physical mixture and tablet of liquisolid formulations F2 showed characteristic distinct peaks mainly for Avicel PH 102, and furo- semide. Thus, there is no undesired interaction between the drug and excipients. It can be noticed a reduction in intensity of the characteristic absorption bands of the drug in liquisolid formulations which might be attributed to the hydrogen bonding interaction of the amino and carboxyl group of furosemide with the hydroxyl group of the liquid vehicles PEG 400 [45].

FTIR spectra of crospovidone and sodium starch glycolate were shown in fig. 10 and 11 respectively, FTIR of co-processed superdisintegrants showed retention of all the major peaks of individual polymer (sodium starch glycolate and crospovidone) which indicates the absence of chemical interaction between polymers during processing as in fig. 12 .

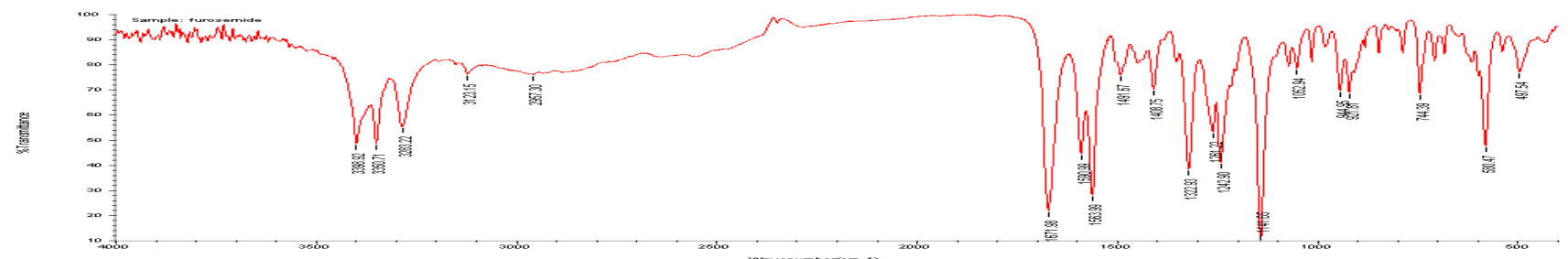

Fig. 7: FTIR spectrum of furosemide

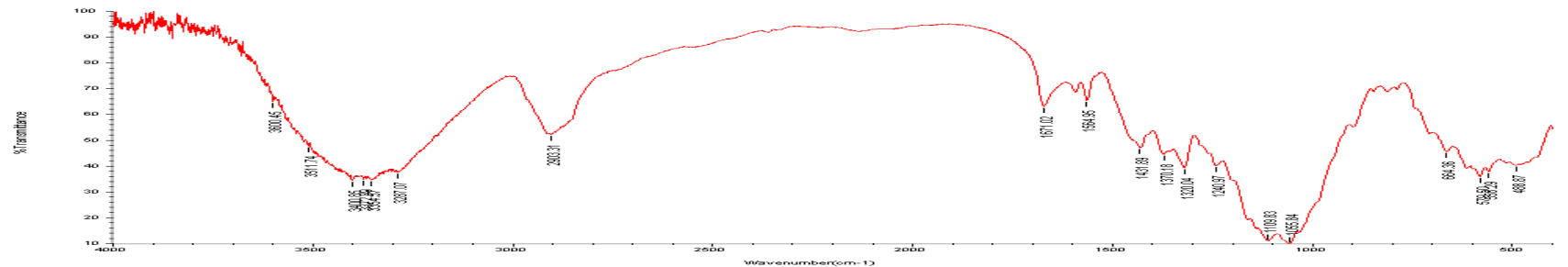

Fig. 8: FTIR spectrum of physical mixture of F2 liquisolid

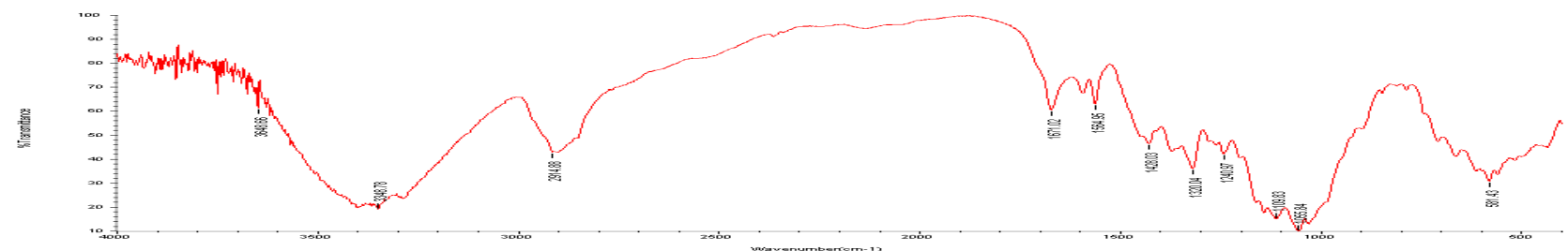

Fig. 9: FTIR spectrum of F2 liquisolid tablet

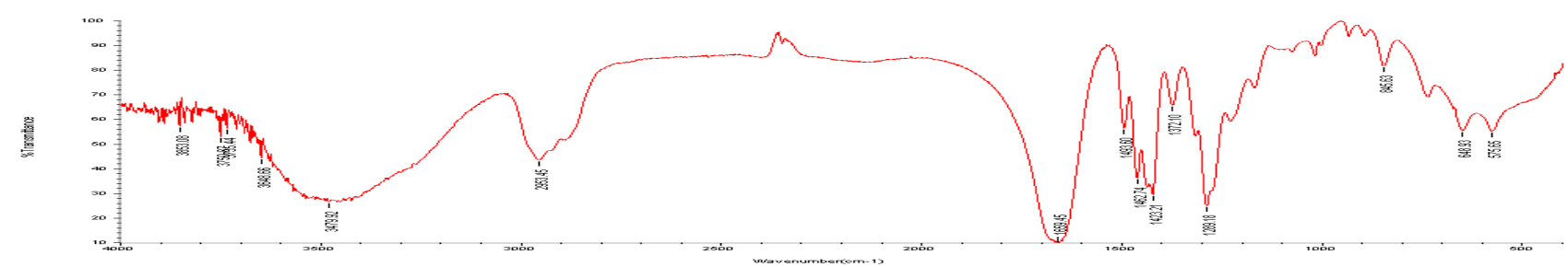

Fig. 10: FTIR spectrum of crospovidone

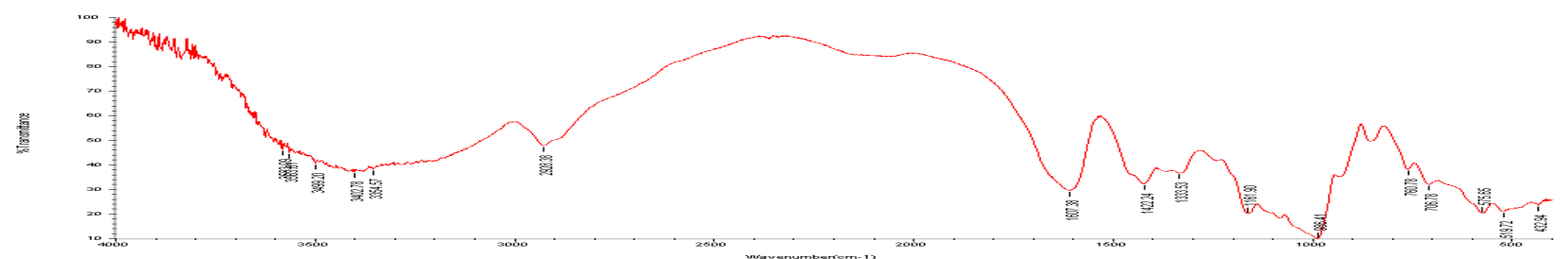

Fig. 11: FTIR spectrum of sodium starch glycolate 


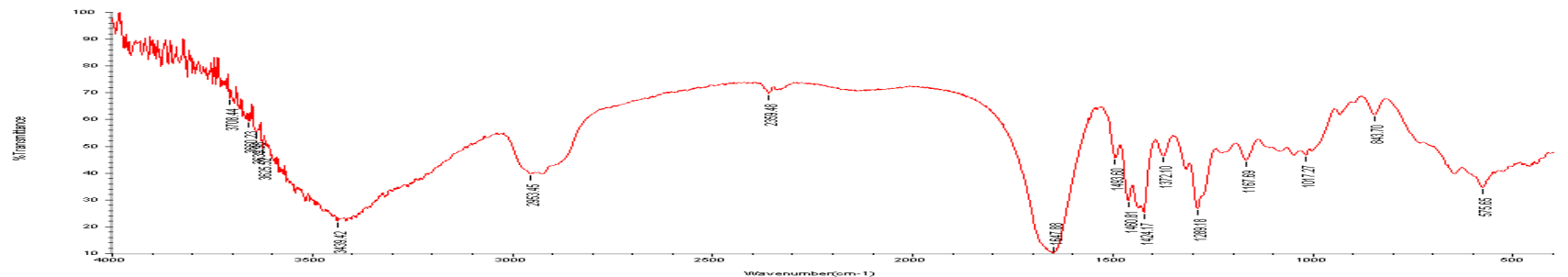

Fig. 12: FTIR spectrum of co-processed superdisintegrants

\section{X-ray powder diffraction (XRPD)}

Fig. 13, 14 and 15 show XRPD of pure furosemide, a physical mixture of F2 liquisolid compact and F2 liquisolid tablet. X-ray diffraction pattern in fig. 13 demonstrated that pure furosemide was clearly in crystalline state as it showed sharp distinct peaks at $2 \theta$ diffraction angles of $6^{\circ}, 22^{\circ}$ and $24^{\circ}$ with high intensity. XRPD pattern of a physical mixture of F2 liquisolid compact and liquisolid tablet in fig. 14 and 15 respectively showed the absence of sharp peaks and appeared as a diffused pattern peaks at $2 \theta$ angles in the $15^{\circ}, 16^{\circ}, 20^{\circ}$ and $22^{\circ}$ with low intensity.

The disappearance of sharp peaks is evident that crystalline pure drug is converted into amorphous state due to its molecular solubilization of the drug in the non-volatile solvent that was absorbed into and adsorbed onto the carrier and coating material, which proves the enhancement of solubility by this technique. Results confirmed the formation of drug solution into a liquisolid system which again supports and confirms the DSC results [46].

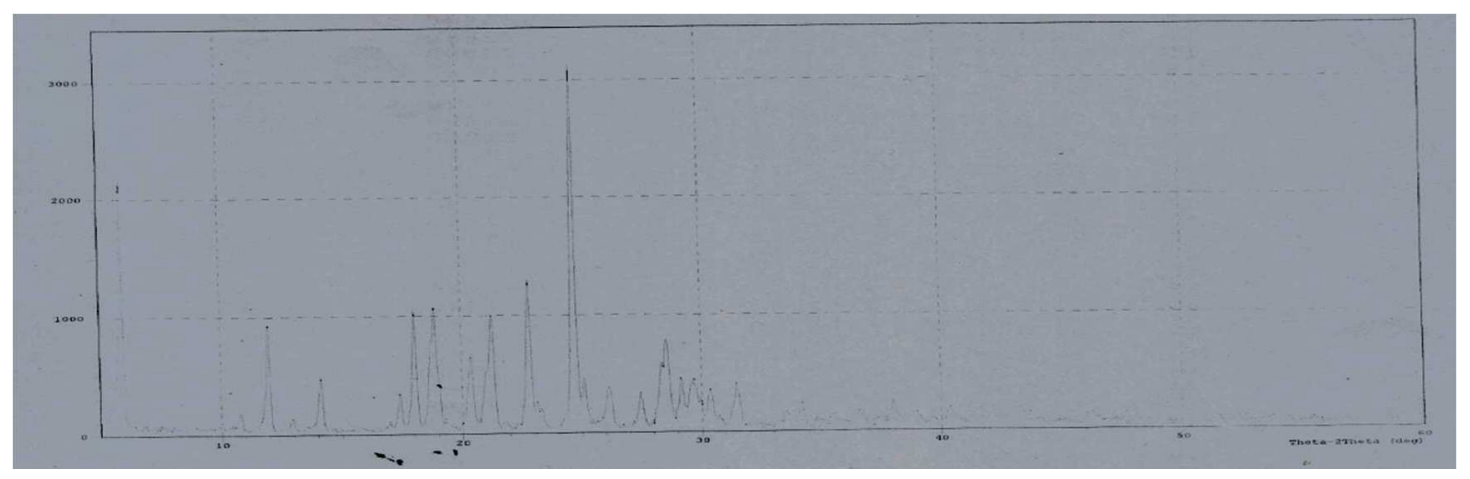

Fig. 13: XRD of furosemide

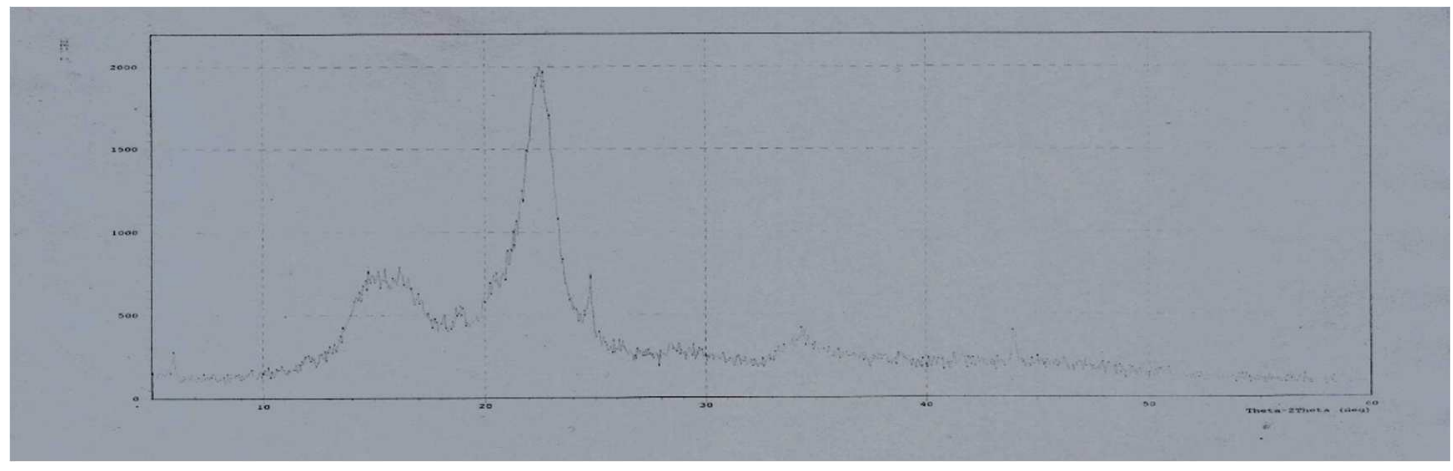

Fig. 14: XRD of physical mixture of F2 liquisolid compact

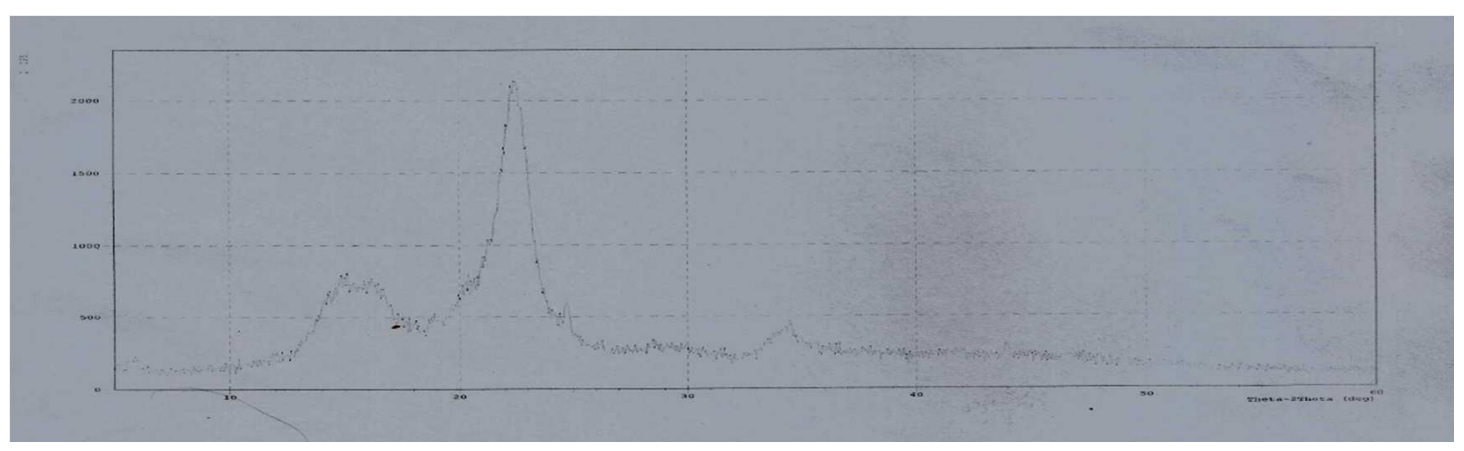

Fig. 15: XRD of F2 liquisolid tablet 


\section{CONCLUSION}

The liquisolid technique succeeded to improve the dissolution rate of the practically insoluble drug such as furosemide. Among the liquisolid tablets tested, F2 prepared using PEG 400 as a non-volatile liquid vehicle, at the R-value of 25 and containing $50 \%$ drug concentration, possessed reasonable flow, rapid dissolution time and the highest dissolution rate compared to other formulations. The results of investigations demonstrate that $40 \mathrm{mg}$ furosemide tablets with acceptable size, mass, fast and entire drug dissolution could be prepared by selection of suitable drug concentration in a liquid vehicle.

\section{ACKNOWLEDGEMENT}

We are thankful to Dr. Nawal Ayash for providing gift sample of furosemide, Avicel PH 102 and grateful to MSc. Mohammed Iqdam Mohammed for his invaluable support and providing necessary facilities to carry out the research work.

\section{CONFLICT OF INTERESTS}

Declared none

\section{REFERENCES}

1. Altememy D, Altememy JJ. Formulation and evaluation of meloxicam liquisolid compact. Int J Pharm Pharm Sci 2014;6:453-63.

2. Vemula S, Radhika K. Liquisolid compact technique for improvement of the dissolution rate of flurbiprofen: formulation and evaluation. J Drug Res Dev 2015;1:2470-1009, 102.

3. Prajila A, Vipin K, Chandran S, Premaletha K, Augusthy A. Formulation and evaluation of deflazacort liquisolid tablets. Int J Res Pharm Sci 2016;6:19-25.

4. Lahmo P, Singh SK, Garg V, Maharshi P, Yadav AK, Gulati M, et al. Influence of formulation parameters on dissolution rate enhancement of piroxicam using the liquisolid technique. Asian J Pharm Clin Res 2016;9:1-6.

5. Kumar Nagabandi V, Ramarao T, Jayaveera K. Liquisolid compacts: a novel approach to enhance bioavailability of poorly soluble drugs. Int J Pharm Biol Sci 2011;1:89-102.

6. Satyajit Panda, R Varaprasad, K Priyanka, Ranjit P Swain. Liquisolid technique: a novel approach for dosage form design. Int J Appl Pharm 2017;9:8-14.

7. Mangal G, Dhobale S. Development of UV spectrophotometric methods and validation for estimation of furosemide in bulk and tablet dosage form by absorbance maxima and area under the curve method. Int J Adv Pharma 2016;5:160-70.

8. Acid F, Acid A, Acefyllinate A, Camphorate A, Persulfate A, Alfa $A$, et al. Martindale: the complete drug reference. Pharmaceutical Press; 2014.

9. Smith H. Diuretics: a review for the pharmacist: a review. SA Pharm J 2014;81:18-21.

10. El-Hammadi M, Awad N. Investigating the use of liquisolid compacts technique to minimize the influence of $\mathrm{pH}$ variations on loratadine release. AAPS PharmSciTech 2012;13:53-8.

11. Spireas S. Liquisolid systems and methods of preparing same. Google Patents; 2002.

12. Kaur M, Bala R, Arora S. Formulation and evaluation of liquisolid compacts of amlodipine besylate. Int Res J Pharm 2013;4:156-60.

13. Gohel MC, Parikh RK, Brahmbhatt BK, Shah AR. Preparation and assessment of novel co-processed superdisintegrant consisting of crospovidone and sodium starch glycolate: a technical note. AAPS PharmSciTech 2007;8:E63-E9.

14. Bhairav BA, Jadhav MS, Saudagar R. Formulation and evaluation of liquisolid tablet of felodipine. World J Pharm Pharm Sci 2016;5:1670-85.

15. Saeedi M, Akbari J, Morteza-Semnani K, Enayati-Fard R, SarReshteh-dar S, Soleymani A. Enhancement of dissolution rate of indomethacin: using liquisolid compacts. Iran J Pharm Res 2011;10:25

16. Mohammed Asif Hussain Mg, T Rama Rao, Maimuna Anjum. Preparation and evaluation of nilvadipine liquisolid compacts. Int J Pharm Pharm Sci 2014;6:1-8.

17. Messa R, Ampati S. Comparative studies for enhancement of the dissolution profile of pitavastatin. Int J Med Nano 2016;3:311-5.
18. Mahendran Baskaran KBT, Gowthamarajan Kuppusamy, Veera, Kollipara VSRKa R. Formulation development of atorvastatin calcium tablets by gel liquisolid compact technique for improving solid-state stability and dissolution profile. J Drug Res Dev 2016;2:1-7.

19. Arun Raj, R AsAKaJ H. Formulation and evaluation of liquisolid tablets of nifedipine. RGUHS J Pharm Sci 2013;3:43-50.

20. Kapoor D, Patel M, Vyas RB, Lad C. Formulation development, optimization and in vitro characterization of liquisolid compacts of an oxicam derivative. J Drug Delivery Ther 2016;6:64-70.

21. Abbas Aaa, Rasool Aaa, Rajab Na. Preparation and comparative evaluation of liquisolid compact and solid dispersion of candesartan cilexetil. Int J Pharm Pharm Sci 2014;6:257-66.

22. Trustees USPCBo, Convention USP, Revision USPCCo, Board NF. The united states pharmacopoeia: National formulary. Supplement. United States; 2006.

23. Deshmukh P. Dissolution enhancement of rosuvastatin calcium by liquisolid compact technique. J Pharm 2013:1-9. http://dx.doi.org/10.1155/2013/315902

24. Sayyad FJ, Tulsankar SL, Kolap UB. Design and development of liquisolid compact of candesartan cilexetil to enhance dissolution. J Pharm Res 2013;7:381-8.

25. Eedara BB, Kankane M, Jukanti R, Nagabandi VK, Bandari S. Enhanced solubility and permeability of exemestane solid dispersion powders for improved oral delivery. J Pharm Inves 2013;43:229-42.

26. Adibkia K, Shokri J, Barzegar-Jalali M, Solduzian M, Javadzadeh Y. Effect of solvent type on retardation properties of diltiazem HCl form liquisolid tablets. Colloids Surf B 2014;113:10-4.

27. Abd-El Bary A, Louis D, Sayed S. Liquisolid tablet formulation as a tool to improve the dissolution of olmesartan medoxomil. Inventi Rapid: NDDS 2014;3:1-8.

28. Rajesh Asija SB, Sangeeta Asija, Alpesh Yadav, Isha Shah. Enhancement of solubility and dissolution of lercanidipine by liquisolid technique. J Chem Pharma Res 2014;6:2680-6.

29. Sanka K, Poienti S, Mohd AB, Diwan PV. Improved oral delivery of clonazepam through liquisolid powder compact formulations: in vitro and ex-vivo characterization. Powder Technol 2014;256:336-44.

30. Elkhodairy KA, Hassan MA, Afifi SA. Formulation and optimization of orodispersible tablets of flutamide. Saudi Pharm J 2014;22:53-61.

31. Singh Y. Martin's physical pharmacy and pharmaceutical sciences: department of pharmaceutics ernest mario school of pharmacy rutgers, the State University of New Jersey; 2006.

32. Javadzadeh, Yousef. Effect of some commercial grades of microcrystalline cellulose on flowability, compressibility, and dissolution profile of piroxicam liquisolid compacts. Drug Dev Ind Pharm 2009;35:243-51.

33. Karia I, Parmar RB. Formulation and evaluation of fast dissolving tablets of olmesartan medoxomil by using coprocessed excipients techique. World J Pharm Pharm Sci 2015;4:1356-73.

34. Patil BS, Rao NR. Formulation and evaluation of fast dissolving granisetron hydrochloride tablets: effect of the functionality of superdisintegrants. Int J Adv Pharm Sci 2011;2:33-9.

35. Gohel MC, Parikh RK, Brahmbhatt BK, Shah AR. Improving the tablet characteristics and dissolution profile of ibuprofen by using a novel co-processed superdisintegrant: a technical note. AAPS PharmSciTech 2007;8:E94-E9.

36. Vranikova B, Gajdziok J, Dolezel P. The effect of superdisintegrants on the properties and dissolution profiles of liquisolid tablets containing rosuvastatin. Pharm Dev Technol 2017;22:138-47.

37. Spireas S, Sadu S. Enhancement of prednisolone dissolution properties using liquisolid compacts. Int J Pharm 1998; 166:177-88.

38. Javadzadeh Y, Siahi-Shadbad M, Barzegar-Jalali M, Nokhodchi A. Enhancement of dissolution rate of piroxicam using liquisolid compacts. Il Farmaco 2005;60:361-5.

39. Nokhodchi A, Javadzadeh Y, Siahi-Shadbad MR, Barzegar-Jalali $M$. The effect of type and concentration of vehicles on the dissolution rate of a poorly soluble drug (indomethacin) from liquisolid compacts. J Pharm Pharm Sci 2005;8:18-25. 
40. Prajapati ST, Bulchandani HH, Patel DM, Dumaniya SK, Patel $\mathrm{CN}$. Formulation and evaluation of liquisolid compacts for olmesartan medoxomil. J Drug Delivery 2013;1-9. http:// dx.doi.org/ 10.1155/2013/870579.

41. Chaulang G, Patil K, Ghodke D, Khan S, Yeole P. Preparation and characterization of solid dispersion tablet of furosemide with crospovidone. Res J Pharm Tech 2008;1:386-9.

42. Aceves JM, Cruz R, Hernandez E. Preparation and characterization of Furosemide-Eudragit controlled release systems. Int J Pharm 2000;195:45-53.

43. Parmar K, Patel J, Sheth N. Fabrication and characterization of liquisolid compacts of Embelin for dissolution enhancement. J Pharm Inves 2014;44:391-8.
44. Chatap VK, Patil PL, Patil SD. In vitro, ex-vivo characterization of furosemide bounded pharmacosomes for improvement of solubility and permeability. Adv Pharm Pharm 2014;2:67-76.

45. Dias RJ, Mali KK, Ghorpade VS, Daulatrao V, Havaldar VRM. Formulation and evaluation of carbamazepine liquisolid compacts using novel carriers. Indian J Pharm Edu Res 2017;51:69-78.

46. Parmar K, Patel J, Sheth N. Formulation and development of embelin liquisolid systems using quality by design approach. J Pharm Inves 2016;46:547-56. 